\title{
Significados en torno al concepto de psicología jurídica*
}

\author{
Meanings of the concept of legal psychology
}

\section{Carolina Gutiérrez de Piñeres B.** \\ Andrea C. Lobo R. Universidad Santo Tomás, Colombia}

Recibido: 15 de agosto de 2014 Revisado: 3 de octubre de 2014 Aceptado: 1 de diciembre de 2014

\section{Resumen}

El siguiente artículo tuvo como objetivo presentar los significados psicológicos que se construyen en torno a la psicología jurídica, por psicólogos, abogados y estudiantes de psicología. Para la recolección de información se utilizó como técnica las Redes Semánticas Naturales. Se encontró que las palabras asociadas al estímulo Psicología Jurídica, son congruentes con las definiciones que tradicionalmente se brindan en torno a la misma, que no son muy distantes los definidores utilizados por cada grupo, que la organización jerárquica que cada grupo le asigna a los definidores es diferente, y que la predominancia es el de relacionar la psicología jurídica con el ejercicio de la psicología forense.

Palabras clave: psicología jurídica, significado psicológico y redes semánticas.

\section{Abstract}

The following article aims to present the psychological meanings that are built around legal psychology, by psychologists, lawyers and students of psychology. Natural Semantic Networks were used to collect and process data. It was found that the words as-

Articulo de investigación.

Correspondencia: Carolina Gutierrez de Piñeres, Facultad de Psicología, Universidad Santo Tomás, Colombia. Dirección postal: Cra. 9 No. 51 - 11. Bogotá, Colombia. Correo electrónico: carolinagdep@yahoo.com 
sociated to the expression "Legal Psychology" are consistent with the traditional definitions; that the definers used by each group are close together, that the hierarchical organization each group assigns to the definer is different, and that the predominance is to relate legal psychology to the practice of forensic psychology.

Keywords: Legal psychology, psychological meaning, semantic networks.

\section{Introducción}

El concepto de psicología jurídica sigue hoy siendo un tema de debate, que cobra importancia en la medida en que lo que se entiende por un campo de conocimiento es lo que orienta la forma en que aquel se ejerce, se práctica, se desarrolla, y dentro del cual se investiga. En otras palabras, los significados que se construyen en torno a la psicología jurídica son los que definen las áreas de trabajo en las que los psicólogos jurídicos se desempeñarán, las funciones que se les asignarán, los contenidos académicos que se enseñaran en la formación de pregrado y en la postgradual, así como los principios epistemológicos y paradigmáticos que orientarán la enseñanza del área, los principios deontológicos que guiarán su ejercicio, los problemas de conocimiento y los objetos de estudio en torno a los cuales se desarrollarán las investigaciones (Gutiérrez de Piñeres, 2011).

La psicología jurídica ha sido entendida como una campo de articulación entre la psicología y el derecho; un área aplicada de la psicología; un área de la psicología social (Gutiérrez de Piñeres, 2011). Estas comprensiones han derivado en discusiones sobre los objetos de estudio que debería abordar, los problemas de conocimiento sobre los que debería profundizar, y sobre los aspectos epistemológicos que deberían orientar su quehacer y desarrollo, por mencionar algunos de los principales debates. Esta falta de consenso puede resultar tan dinamizadora como obstaculizadora del desarrollo de la psicología jurídica, ya que la noción subjetiva que tienen las personas sobre determinados conceptos determinan en parte la forma en que se posicionarán frente a aquellos.
Una forma de comprender los significados subjetivos que se construyen en torno al concepto de psicología jurídica es la utilización de redes semánticas, a través de las cuales es posible conocer las diferencias entre lo que se quiere dar a entender por un concepto cuando este se define, y lo que las personas que entran en contacto con ese concepto entienden por aquel. Las expresiones que utilizan en su lenguaje cotidiano develan el entendimiento que las personas tienen de un concepto, habiendo sido atravesado por una conceptualización académica o científica, afectando las relaciones sociales (Cole y Scribner, 1977) y la relación de la palabra con la realidad (Chomsky, 1971). Cuando existe ambigüedad en la comunicación que se da entre dos personas, se minimiza la eficacia en la comunicación (Freedman, Carlsmith y Sears, 1979).

En 1967, Quilian acuñó el término de red semántica, con el fin de explicar la organización del significado de las palabras aprendido y almacenado en la memoria semántica, a partir de una simulación computacional, utilizando un modelo matemático que permitiera ampliar la investigación sobre un tema o fenómeno particular. Este modelo de red semántica se inscribió en una de los modelos de procesamiento de la información, conocido como modelo de memoria asociativa humana (HAM, por sus siglas en inglés), el cual parte de dos supuestos: 1) las representaciones mentales se relacionan entre sí, reproduciendo en su estructura la estructura del mundo; y 2) el conjunto de relaciones que se tiene con otros conceptos forman una red de conceptos que en conjunto determinan el significado del nuevo concepto que emerge y que hace que este pueda diferenciarse de otros similares (Quillian, 1968). 
Posteriormente, Figueroa, González y Solís (1981) propusieron utilizar este mismo método para conocer la forma en que se organizaba el conocimiento humano y la forma en que las palabras se relacionaban para construir significados, para lo cual acuñaron el término redes semánticas naturales.

En esta esta investigación, la utilización de redes semánticas permitió conocer algunos de los significados en torno al concepto de psicología jurídica, entendiendo que una palabra por sí sola no forma un concepto, pero que una sola palabra puede ser "el símbolo abstracto que marca el límite conceptual del objeto" (Labastida, 2007, p. 12), y, por lo tanto, en esta investigación se buscaron los conceptos enlazados con las palabras psicología jurídica, de modo que pudieran constituirse entidades conceptuales que retraten el objeto que la psicología jurídica quiere significar, de forma tal que pueda ser comprendida tanto por una comunidad científica como por personas que se relacionen con ella.

Álvaro, Garrido, Schweiger y Torregosa (2007) sostienen que los conceptos "funcionan como un mapa inicial del territorio delimitado por un campo del conocimiento y legitiman la investigación marcando los límites y [...] las fronteras" (p. 18), permitiendo que los campos de conocimiento se desarrollen a partir de unos referentes lógicos, epistemológicos, paradigmáticos, teleológicos, pragmáticos y metodológicos, definidos por el acuerdo al que llega una comunidad científica frente a lo que se entenderá por aquel. Una forma de conocer los conceptos y características de un campo de conocimiento es a través de la utilización de redes semánticas.

El concepto de redes semánticas ha tenido varias evoluciones, y hoy una de las más aceptadas es la propuesta por Collins y Loftus (1975), conocida como la teoría extendida de propagación de la activación, que pretende explicar el funcionamiento de la memoria humana, especialmente de la memoria semántica, la cual permite que pueda accederse a los recuerdos de los significados de los conceptos.

La memoria semántica no tiene referentes en el tiempo ni en el espacio, por lo tanto, no es posible saber cuándo se aprendió el significado de un concepto, pero es posible evocar los significados gracias, en parte, a la proximidad de unos recuerdos que están relacionados, de modo que al evocarse un concepto, se produce una propagación de esta activación hacia otros conceptos relacionados de manera lógica. Este proceso, según Collins y Loftus (1975), permite que se organicen los conceptos.

Para Collins y Loftus (1975), un concepto se representa entonces como un nodo en una red, cuyas propiedades y conexiones son representadas como vínculos etiquetados con otros nodos, los cuales tienen diferente peso frente a un concepto, de acuerdo con qué tan esencial resulte el vínculo para el significado que adquiere un concepto, y qué tanta cercanía tienen en el recuerdo estos conceptos.

Estos vínculos van dando origen a categorías, que dentro de un concepto pueden hacer referencia, por ejemplo, al género al que pertenece o a las funciones que tiene, así como permiten la aparición de palabras que describen las propiedades del concepto. Qué tan fácil o rápido se asocia una palabra a otra depende de qué tan relacionadas semánticamente se encentren; a esto se le conoce como priming semántico (por ejemplo, es más probable que junto a la palabra manzana aparezca la palabra naranja o fruta, que la palabra madera o silla).

El concepto sobre el cual se produce una respuesta se conoce como blanco, y el concepto o conceptos subsiguientes que se activan se denominan prime, los cuales son causados por la relación de significado entre diferentes conceptos, por relaciones asociativas, o por la distancia o similitud semántica que exista entre dos conceptos (Collins y Loftus, 1975).

Se espera, a partir del modelo de propagación de la activación, que se den varios supuestos: 1) que una vez se estimule un concepto, este active otros conceptos relacionados; 2) que cuanto mayor sea la activación de un concepto en una red, mayor sea la activación propagada; 3) que el nivel de activación decrezca con el tiempo y con la actividad, con el fin de no saturar el sistema de memoria semántica; 4) que la cantidad de conceptos 
que se activan por diversos caminos adquieran un significado para ser comprendidos; 5) que las redes se organicen de acuerdo con sus similitudes semánticas; 6) que los nombres de los conceptos se almacenen en una memoria lexical, cuya organización deriva en similitudes más fonológicas y menos ortográficas; y 7) que la persona pueda controlar la propagación de la activación de la red semántica.

A partir de lo anterior el objetivo de este artículo es dar a conocer el conjunto de palabras que para psicólogos, abogados y estudiantes de psicología conforman el significado y el concepto del término psicología jurídica. El alcance de los resultados se espera que contribuya a ampliar las construcciones que se han hecho en torno a la psicología jurídica, y, por lo tanto, que sirva para enriquecer los marcos teóricos y conceptuales utilizados para el desarrollo de este campo de conocimiento.

\section{Método}

\section{Participantes}

Para la selección de los participantes se utilizó un muestreo no probabilístico incidental, en el cual participaron 135 personas ( 90 psicólogos, 20 abogados, 25 estudiantes de psicología).

\section{Técnica}

Para la recolección de información se utilizaron como técnica las redes semánticas naturales modificadas (RSNM), las cuales exploran, a partir de una aproximación cualitativa, el significado psicológico de un concepto, con base en los núcleos de la red, los elementos más próximos a cada uno y la organización cognoscitiva en forma de red en torno a una palabra-estímulo (Reyes, 1993).

Esta es una técnica para el estudio de la representación y utilización de la información en la memoria, usada para la determinación del significado de un concepto (Figueroa, González y Solís, 1981). Según Tulving (citado en Zermeño et al., 2005), las RSNM se vinculan al estudio de la cognición social, que incluye una serie de procesos psicológicos a partir de los cuales se obtiene, usa, almacena y modifica el conocimiento que se tiene del mundo y de las personas. Esta técnica se basa en la idea según la cual la memoria semántica se encarga de organizar los significados y conceptos sobre las cosas y las relaciones entre estas.

\section{Instrumentos y procedimiento}

Se construyó un instrumento formado por dos hojas formato 1/4 carta. En la primera hoja, los participantes tenían las instrucciones y un ejemplo, y en la segunda, la palabra estímulo psicología jurídica. Se solicitó a los participantes escribir al menos cinco palabras entre sustantivos, adjetivos, verbos y adverbios para el estímulo que se les presentó, en un tiempo máximo de dos minutos. Este tiempo debía ser limitado, porque se pretendía acceder a la memoria semántica sin análisis sobre el significado de las palabras que se asociaban al estímulo.

Posteriormente se les pidió que jerarquizaran las palabras de acuerdo con la importancia que cada una de ellas tuviera con respecto al estímulo, de manera que se le asignará el número uno a la palabra más importante, el número dos a la segunda palabra más importante, y así sucesivamente, hasta terminar la lista.

La aplicación del instrumento fue grupal y el tiempo empleado para contestar fue aproximadamente de cinco minutos.

\section{Análisis de datos y tratamiento estadístico}

El análisis de la red semántica se realizó a partir del protocolo de las RSNM, propuesto por Domínguez (s. f.), en el cual se utiliza el programa Excel. Esta propuesta incluye al menos ocho tipos de análisis, algunos de carácter obligatorio y otros más flexibles. En esta investigación se hacen los cuatro análisis obligatorios.

Dentro del análisis se "contempla que se pueden juntar en la misma categoría aquellas palabras 
que solamente cambian su género, su número o bien, que evidentemente se refieren exactamente a lo mismo. Ejemplo: lento-lenta, audaz-audaces, polución contaminación" (Domínguez, s. f., p. 2).

El primer paso consiste en obtener el tamaño de red (TR), es decir, encontrar la cantidad de definidores que se asociaron al estímulo. Para ello se hace un análisis de Chi cuadrado, lo cual permite obtener el TR para cada grupo de participantes, en nuestro caso psicólogos, estudiantes de psicología y abogados.

El segundo paso lleva a obtener el peso semántico (PS), el cual "simboliza la importancia adjudicada a cada palabra en la representación de un concepto mediante ponderaciones" (Domínguez, s. f., p. 7).

Posteriormente se calcula la distancia semántica cuantitativa (DS), la cual permite separar las palabras definidoras del estímulo en sí, permitiendo identificar cuáles se encuentran en la red, más cercanas o más lejanas del núcleo.

A continuación se identifica el núcleo de la red (NR). Este representa el conjunto de palabras que están más cercanas al estímulo, y que por lo tanto constituyen los definidores más importantes. Para su representación se utiliza una gráfica de líneas o una gráfica radial.

\section{Consideraciones éticas}

Sobre inclusión y participación de las personas que hicieron parte de la investigación: Se contactó a los posibles participantes, a quienes se les explicó el proyecto y se les invitó a formar parte de la investigación de manera voluntaria. Su acep- tación se plasmó en un consentimiento informado, que dejó señalado de manera explícita las condiciones de su participación y las estrategias para la devolución de resultados.

En el desarrollo de la investigación, y particularmente en la aplicación de los instrumentos, se tuvieron en cuenta los principios planteados en el informe Belmont de autonomía, beneficencia, no maleficencia y justicia. Del mismo modo se consideraron las pautas internacionales para la investigación biomédica en seres Humanos (CIOMS, 1982), y la ley del psicólogo, que, además, contiene el código deontológico y bioético de psicología (Ley 1090 de 2006).

\section{Resultados}

A partir de los resultados, se observa que el grupo que mayor número de definidores produjo fue el de psicólogos. En este grupo se obtuvo un total de 153 palabras definidoras, después de eliminar las que se consideraban sinónimos, o las que se encontraban repetidas, de las cuales se presentan en la tabla 1 las 30 primeras, de acuerdo con el peso semántico alcanzado por cada una.

En la tabla 1 se puede leer que la palabra que mayor peso semántico y menor distancia semántica obtuvo fue derecho. En este grupo, esta palabra se convierte en el núcleo de la red, lo cual indica que se encuentra semánticamente más relacionada con la psicología jurídica en este grupo. En las figuras 1 y 2 , que se muestran a continuación, puede verse que a la palabra derecho le siguen en orden, de acuerdo con el peso semántico, las palabras leyes, comportamiento, forense, víctimas, justicia, peritaje y evaluación. 
Tabla 1.

Principales definidores obtenidos en la muestra de psicólogos

\begin{tabular}{|c|c|c|c|c|c|}
\hline \multirow{2}{*}{$\begin{array}{c}\text { TR } \\
\text { (tamaño } \\
\text { de red) }\end{array}$} & \multirow{2}{*}{$\begin{array}{l}\text { Palabras } \\
\text { Derecho }\end{array}$} & \multirow{2}{*}{$\begin{array}{l}\mathrm{FR} \\
26 \\
\end{array}$} & \multirow{2}{*}{$\begin{array}{l}\text { PS } \\
230 \\
\end{array}$} & \multicolumn{2}{|c|}{$\begin{array}{c}\text { DSC } \\
\text { (distancia semántica cuantitativa }\end{array}$} \\
\hline & & & & $100,0 \%$ & 0,00 \\
\hline 2 & Leyes & 24 & 179 & $77,8 \%$ & 0,22 \\
\hline 3 & Comportamiento & 17 & 153 & $66,5 \%$ & 0,33 \\
\hline 4 & Forense & 17 & 140 & $60,9 \%$ & 0,39 \\
\hline 5 & Víctimas & 17 & 139 & $60,4 \%$ & 0,40 \\
\hline 6 & Justicia & 16 & 130 & $56,5 \%$ & 0,43 \\
\hline 7 & Peritaje & 13 & 110 & $47,8 \%$ & 0,52 \\
\hline 8 & Evaluación & 13 & 108 & $47,0 \%$ & 0,53 \\
\hline 9 & Ciencia & 8 & 73 & $31,7 \%$ & 0,68 \\
\hline 10 & Norma & 9 & 72 & $31,3 \%$ & 0,69 \\
\hline 11 & Criminología & 9 & 66 & $28,7 \%$ & 0,71 \\
\hline 12 & Especialidad & 7 & 66 & $28,7 \%$ & 0,71 \\
\hline 13 & Investigación & 8 & 65 & $28,3 \%$ & 0,72 \\
\hline 14 & Legal & 8 & 60 & $26,1 \%$ & 0,74 \\
\hline 15 & Área & 6 & 60 & $26,1 \%$ & 0,74 \\
\hline 16 & Conocimiento & 7 & 59 & $25,7 \%$ & 0,74 \\
\hline 17 & Psicología & 7 & 57 & $24,8 \%$ & 0,75 \\
\hline 18 & Conducta & 6 & 57 & $24,8 \%$ & 0,75 \\
\hline 19 & Testimonio & 7 & 56 & $24,3 \%$ & 0,76 \\
\hline 20 & Rama & 5 & 50 & $21,7 \%$ & 0,78 \\
\hline 21 & Apoyo & 6 & 45 & $19,6 \%$ & 0,80 \\
\hline 22 & Asesoría & 5 & 42 & $18,3 \%$ & 0,82 \\
\hline 23 & Perito & 5 & 38 & $16,5 \%$ & 0,83 \\
\hline 24 & Contexto legal & 4 & 35 & $15,2 \%$ & 0,85 \\
\hline 25 & Juicio & 5 & 34 & $14,8 \%$ & 0,85 \\
\hline 26 & Victimología & 5 & 34 & $14,8 \%$ & 0,85 \\
\hline 27 & Penitenciaria & 5 & 33 & $14,3 \%$ & 0,86 \\
\hline 28 & Conflicto & 4 & 33 & $14,3 \%$ & 0,86 \\
\hline 29 & Jurídico & 4 & 30 & $13,0 \%$ & 0,87 \\
\hline 30 & Audiencia & 3 & 30 & $13,0 \%$ & 0,87 \\
\hline
\end{tabular}

Fuente: elaboración propia 
Figura 1. Red del estímulo psicología jurídica, a partir de las palabras definidoras obtenidas en el grupo de psicólogos

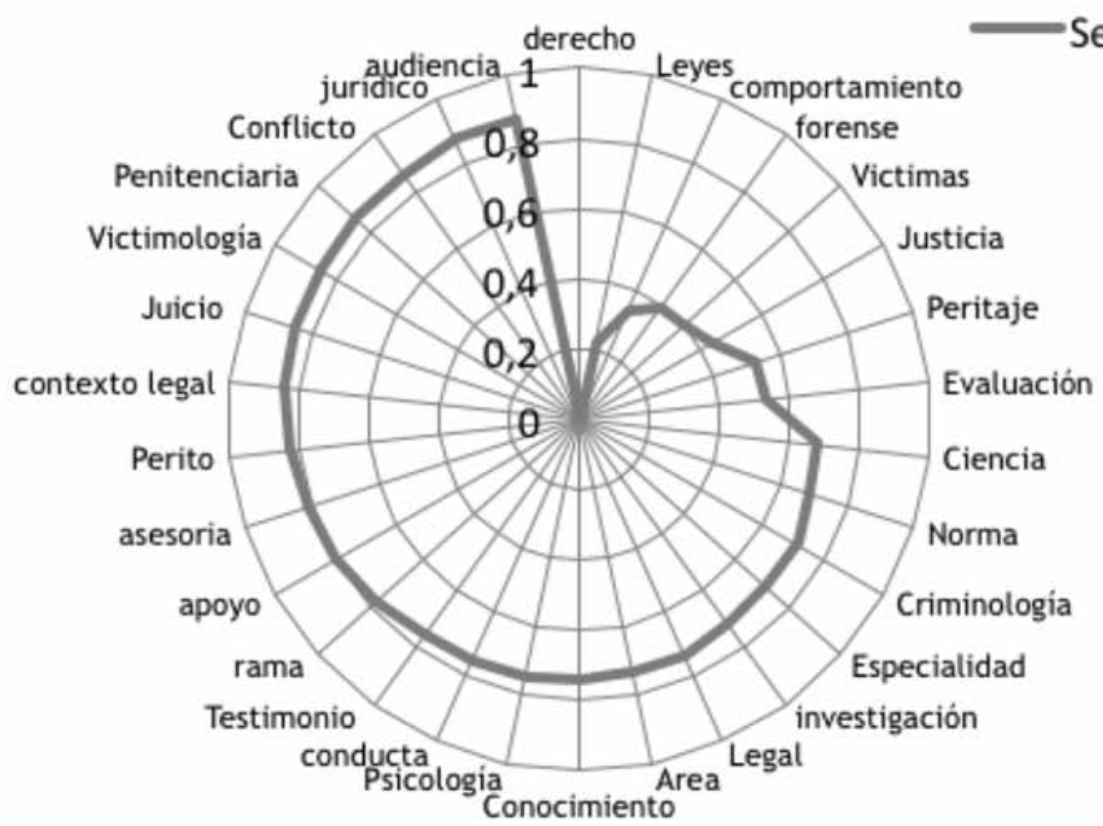

Fuente: elaboración propia

Figura 2. Distancia semántica de las palabras definidoras del estímulo psicología jurídica, a partir de las palabras definidoras obtenidas en el grupo de psicólogos

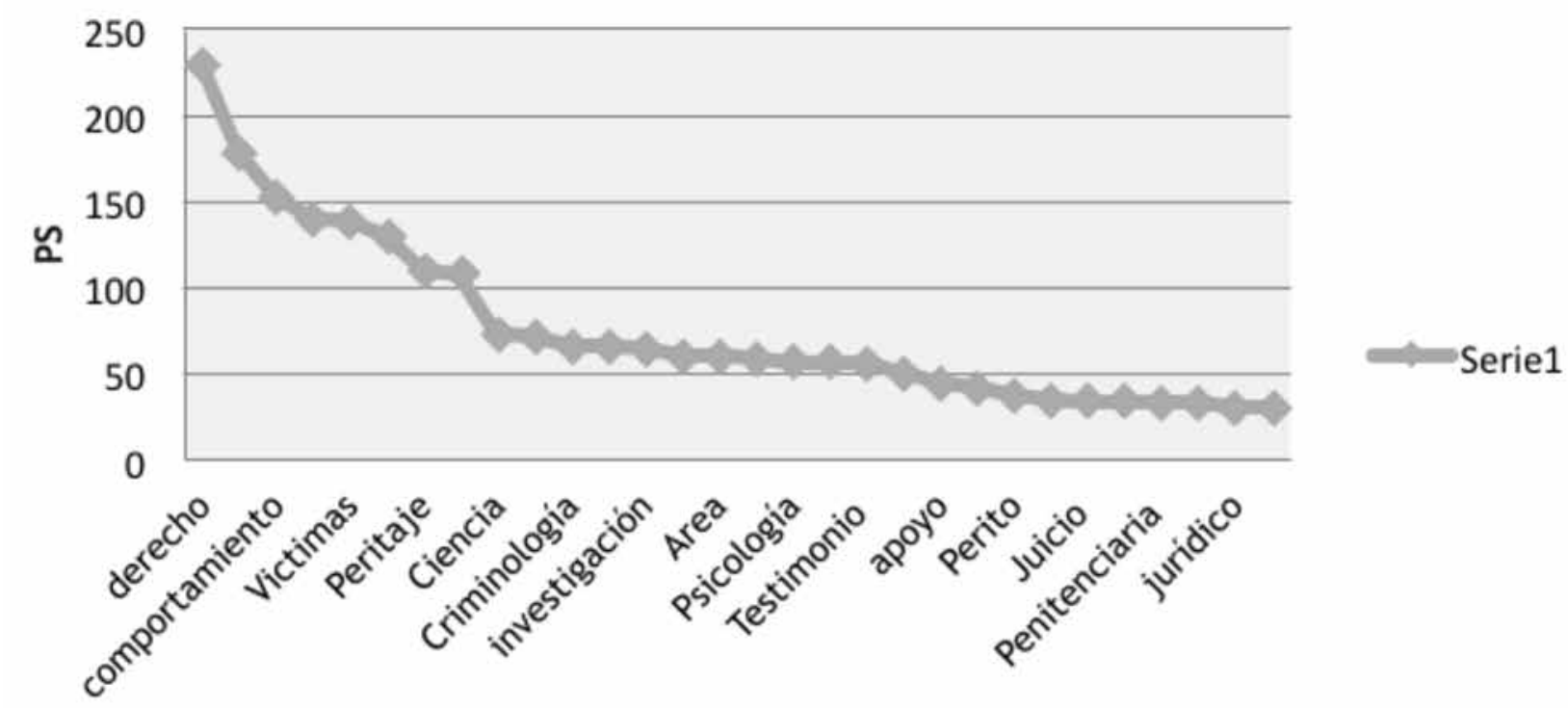

Fuente: elaboración propia 
De otro lado, la tabla 2 permite ver, de los 153 definidores, los 10 que tenían la mayor distancia semántica en el grupo de psicólogos.

El segundo grupo fue el de estudiantes de psicología. En este se obtuvo un total de 82 palabras definidoras, después de eliminar las que se consideraban sinónimos o las que se encontraban repe- tidas. En la tabla 3 se presentan las 30 palabras que alcanzaron el mayor peso semántico.

En el grupo de estudiantes, el nucleo de la red es la palabra derecho, seguida por las palabras justicia y leyes, las cuales no presentan una distnacia muy amplia respecto de la que configura el nucleo de la red, como puede notarse en las figuras 3 y 4.

Tabla 2

Palabras definidoras que obtuvieron el menor peso semántico en la muestra de psicólogos

\begin{tabular}{cccccc}
\hline $\begin{array}{c}\text { TR } \\
\text { (tamaño } \\
\text { de red) }\end{array}$ & Palabras & FR & PS & $\begin{array}{c}\text { DSC (distancia semántica } \\
\text { cuantitativa) }\end{array}$ \\
\hline 143 & Inocentes & 1 & 6 & $3 \%$ & 0,97 \\
\hline 144 & Internacional & 1 & 6 & $3 \%$ & 0,97 \\
\hline 145 & Multidisciplinario & 1 & 6 & $3 \%$ & 0,97 \\
\hline 146 & Pensamiento & 1 & 6 & $3 \%$ & 0,97 \\
\hline 147 & Problemas Psicológicos & 1 & 6 & $3 \%$ & 0,97 \\
\hline 148 & Procedimiento & 1 & 6 & $3 \%$ & 0,97 \\
\hline 149 & Reclusos & 1 & 6 & $3 \%$ & 0,97 \\
\hline 150 & Relaciones interpersonales & 1 & 6 & $3 \%$ & 0,97 \\
\hline 151 & Secuelas & 1 & 6 & $3 \%$ & 0.97 \\
\hline 152 & Sistema & 1 & 6 & $3 \%$ & 0.97 \\
\hline 153 & Toma de decisiones & 1 & 6 & $3 \%$ & 0.97 \\
\hline
\end{tabular}

Fuente: elaboración propia

Tabla 3

Principales definidores obtenidos en la muestra de estudiantes de psicología

\begin{tabular}{cccccc}
\hline $\begin{array}{c}\text { TR } \\
\text { (tamaño } \\
\text { de red) }\end{array}$ & Palabras & FR & PS & $\begin{array}{c}\text { DSC (distancia semántica } \\
\text { cuantitativa) }\end{array}$ \\
\hline 1 & Derecho & 8 & 68 & $100,0 \%$ & 0,00 \\
\hline 2 & Justicia & 7 & 65 & $95,6 \%$ & 0,04 \\
\hline 3 & Leyes & 7 & 57 & $83,8 \%$ & 0,16 \\
\hline 4 & Testimonio & 6 & 50 & $73,5 \%$ & 0,26 \\
\hline 5 & Delito & 5 & 35 & $51,5 \%$ & 0,49 \\
\hline 6 & Forense & 4 & 34 & $50,0 \%$ & 0,50 \\
\hline 7 & Peritaje & 4 & 34 & $50,0 \%$ & 0,50 \\
\hline 8 & Víctima & 4 & 32 & $47,1 \%$ & 0,53 \\
\hline 9 & Intervención & 4 & 31 & $45,6 \%$ & 0,54 \\
\hline 10 & Credibilidad & 3 & 23 & $33,8 \%$ & 0,66 \\
\hline 11 & Victimario & 3 & 20 & $29,4 \%$ & 0,71 \\
\hline 12 & Rama & 2 & 20 & $29,4 \%$ & 0,71 \\
\hline 13 & Ciencia & 2 & 19 & $27,9 \%$ & 0,72 \\
\hline
\end{tabular}




\begin{tabular}{cccccc}
\hline $\begin{array}{c}\text { TR } \\
\text { (tamaño } \\
\text { de red) }\end{array}$ & Palabras & FR & PS & $\begin{array}{c}\text { DSC (distancia semántica } \\
\text { cuantitativa) }\end{array}$ \\
\hline 14 & Comportamiento & 2 & 19 & $27,9 \%$ & 0,72 \\
\hline 15 & Humano & 3 & 18 & $26,5 \%$ & 0,74 \\
\hline 16 & Investigación & 3 & 17 & $25,0 \%$ & 0,75 \\
\hline 17 & Grado de consanguinidad & 2 & 17 & $25,0 \%$ & 0,75 \\
\hline 18 & Igualdad & 2 & 16 & $23,5 \%$ & 0,76 \\
\hline 19 & Interdisciplinar & 2 & 16 & $23,5 \%$ & 0,76 \\
\hline 20 & Evaluación & 2 & 15 & $22,1 \%$ & 0,78 \\
\hline 21 & Violencia & 2 & 15 & $22,1 \%$ & 0,78 \\
\hline 22 & Psicología & 2 & 14 & $20,6 \%$ & 0,79 \\
\hline 23 & Juzgado & 2 & 13 & $19,1 \%$ & 0,81 \\
\hline 24 & Pruebas & 2 & 12 & $17,6 \%$ & 0,82 \\
\hline 25 & Conducta & 2 & 10 & $14,7 \%$ & 0,85 \\
\hline 26 & Aplicación de instrumentos & 1 & 10 & $14,7 \%$ & 0,85 \\
\hline 27 & Código civil & 1 & 10 & $14,7 \%$ & 0,85 \\
\hline 28 & Contextos jurídicos & 1 & 10 & $14,7 \%$ & 0,85 \\
\hline 29 & Habilidades & 1 & 10 & $14,7 \%$ & 0,85 \\
\hline 30 & Perito & 1 & 10 & $14,7 \%$ & 0,85 \\
\hline
\end{tabular}

Fuente: elaboración propia

Figura 3. Red del estímulo psicología jurídica a partir de las palabras definidoras obtenidas en el grupo de estudiantes de psicología

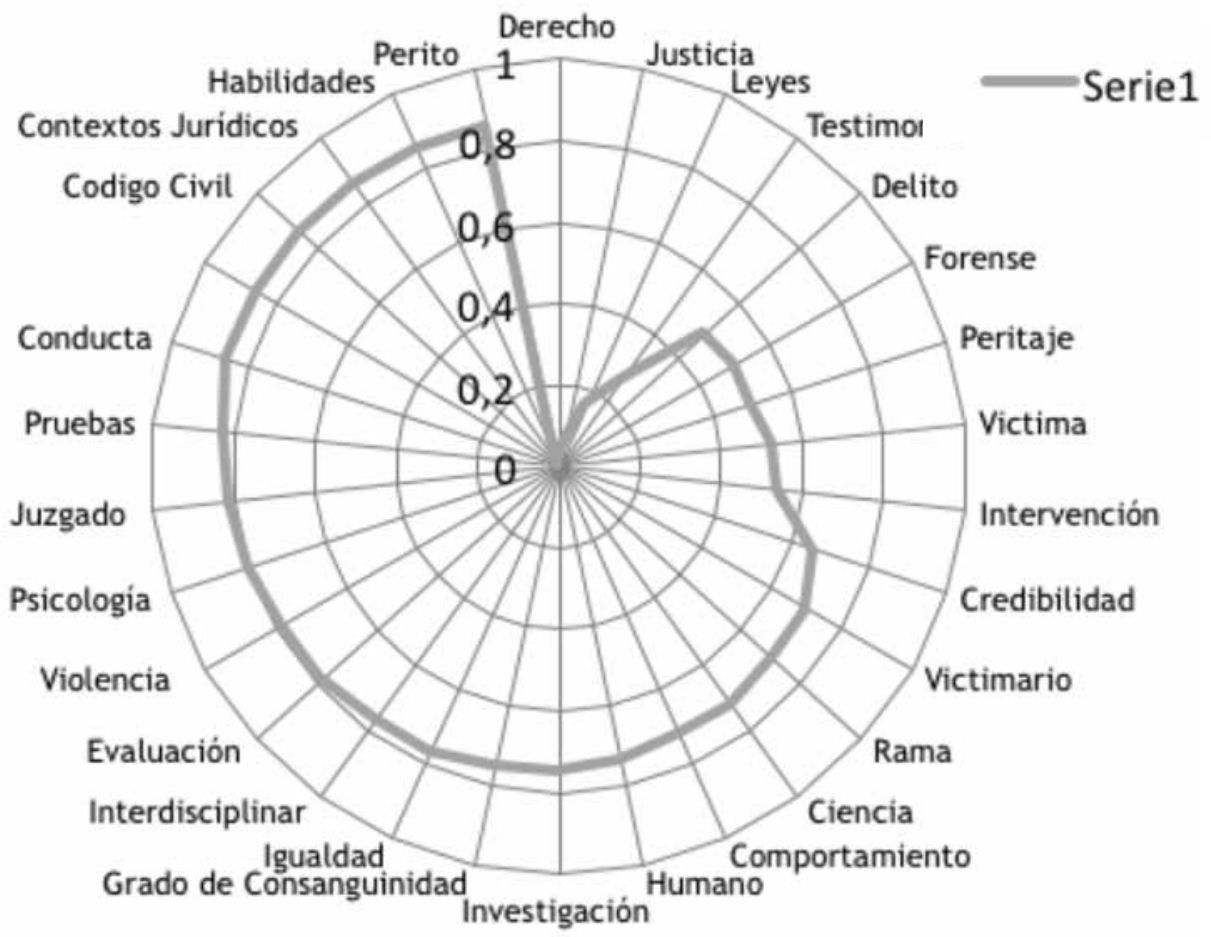

Fuente: elaboración propia 
Figura 4. Distancia semántica de los palabras definidoras del estímulo psicología jurídica a partir de las palabras definidoras obtenidas en el grupo de estudiantes de psicología

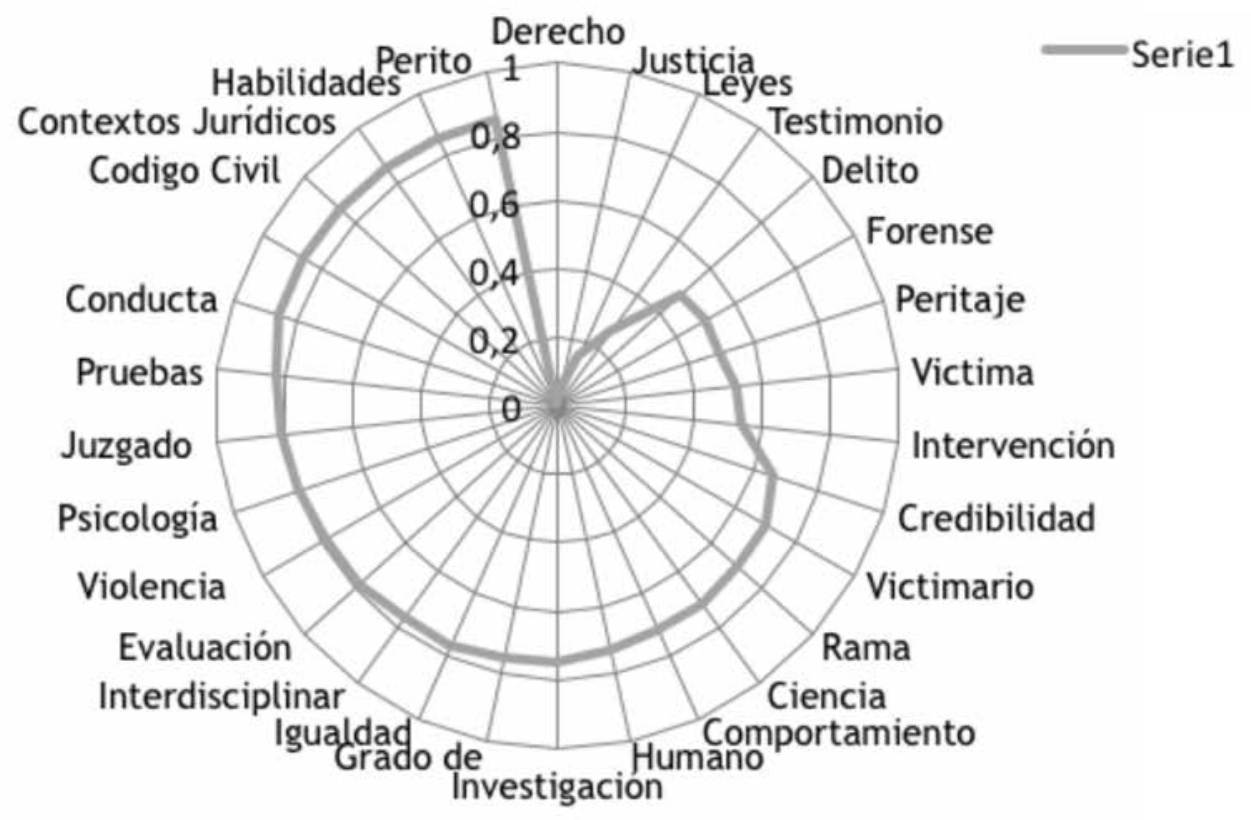

Fuente: elaboración propia

La tabla 4 nos permite ver de los 82 definidores, los 10 que tenían la mayor distancia semántica, en el grupo de estudiantes de psicología.

Llama la atención cómo tanto en el grupo de psicólogos como en el de estudiantes de psicología la palabra que mayor peso semántico produjo fue la palabra derecho, mientras que para el grupo de abogados, en el cual se obtuvo un total de 67 definidores (ver tabla 5), la palabra con el mayor peso semántico fue ciencia.

En el caso del grupo de abogados, se obtuvo un total de 67 palabras definidoras, después de elimi-

Tabla 4

Palabras definidoras que obtuvieron el menor peso semántico en la muestra de estudiantes de psicología

\begin{tabular}{cccccc}
\hline $\begin{array}{c}\text { TR (tamaño de } \\
\text { red) }\end{array}$ & Palabras & FR & PS & DSC (distancia semántica cuantitativa) \\
\hline 72 & Método & 1 & 3 & $4 \%$ & 0,95 \\
\hline 73 & Disciplina & 1 & 2 & $3 \%$ & 0,97 \\
\hline 74 & Deber & 1 & 1 & $1 \%$ & 0,98 \\
\hline 75 & Empalmar & 1 & 1 & $1 \%$ & 0,98 \\
\hline 76 & Estudio & 1 & 1 & $1 \%$ & 0,98 \\
\hline 77 & Expansión & 1 & 1 & $1 \%$ & 0,98 \\
\hline 78 & Incorporar & 1 & 1 & $1 \%$ & 0,98 \\
\hline 79 & Necesaria & 1 & 1 & $1 \%$ & 0,98 \\
\hline 80 & Personas & 1 & 1 & $1 \%$ & 0,98 \\
\hline 81 & Útil & 1 & 1 & $1 \%$ & 0,98 \\
\hline 82 & Vincular & 1 & 1 & $1 \%$ & 0,98 \\
\hline
\end{tabular}

Fuente: elaboración propia 
nar las que se consideraban sinónimos, o las que se encontraban repetidas. En la tabla 5 se muestran las 30 palabras que alcanzaron el mayor peso semántico y la menor distancia semántica.

La tabla 6 permite ver, de los 67 definidores, los 10 que tenían la mayor distancia semántica en el grupo de abogados.
En el grupo de estudiantes, el núcleo de la red es la palabra derecho, seguida por las palabras justicia y leyes, las cuales no presentan una distnacia muy amplia respecto de la que configura el nucleo de la red, como puede notarse en las figuras 5 y 6 .

Para el caso del grupo de abogados que participó en este estudio, a la palabra ciencia, que ocupa el

Tabla 5

Principales definidores obtenidos en la muestra de abogados

\begin{tabular}{|c|c|c|c|c|c|}
\hline \multirow{2}{*}{$\begin{array}{c}\text { TR (tamaño } \\
\text { de red) }\end{array}$} & \multirow{2}{*}{$\begin{array}{l}\text { Palabras } \\
\text { Ciencia }\end{array}$} & \multirow{2}{*}{$\begin{array}{c}\text { FR } \\
7\end{array}$} & \multirow{2}{*}{$\begin{array}{l}\text { PS } \\
67\end{array}$} & \multicolumn{2}{|c|}{$\begin{array}{c}\text { DSC (distancia semántica } \\
\text { cuantitativa) }\end{array}$} \\
\hline & & & & $100,0 \%$ & 0,000 \\
\hline 2 & Análisis & 7 & 57 & $85,1 \%$ & 0,149 \\
\hline 3 & Valoración & 5 & 45 & $67,2 \%$ & 0,328 \\
\hline 4 & Comportamiento & 4 & 34 & $50,7 \%$ & 0,493 \\
\hline 5 & Derecho & 3 & 25 & $37,3 \%$ & 0,627 \\
\hline 6 & Estudio & 3 & 24 & $35,8 \%$ & 0,642 \\
\hline 7 & Proceso & 3 & 24 & $35,8 \%$ & 0,642 \\
\hline 8 & Pericia & 3 & 21 & $31,3 \%$ & 0,687 \\
\hline 9 & Conducta & 2 & 20 & $29,9 \%$ & 0,701 \\
\hline 10 & Conocimiento & 2 & 20 & $29,9 \%$ & 0,701 \\
\hline 11 & Especialidad & 2 & 19 & $28,4 \%$ & 0,716 \\
\hline 12 & Interpretación & 2 & 17 & $25,4 \%$ & 0,746 \\
\hline 13 & Justicia & 2 & 17 & $25,4 \%$ & 0,746 \\
\hline 14 & Pensamiento & 2 & 17 & $25,4 \%$ & 0,746 \\
\hline 15 & Herramienta & 2 & 15 & $22,4 \%$ & 0,776 \\
\hline 16 & Importante & 2 & 15 & $22,4 \%$ & 0,776 \\
\hline 17 & Profesión & 2 & 15 & $22,4 \%$ & 0,776 \\
\hline 18 & Psiquis & 2 & 15 & $22,4 \%$ & 0,776 \\
\hline 19 & Auxiliar & 2 & 12 & $17,9 \%$ & 0,821 \\
\hline 20 & Clara & 1 & 10 & $14,9 \%$ & 0,851 \\
\hline 21 & Condición Humana & 1 & 10 & $14,9 \%$ & 0,851 \\
\hline 22 & Diagnóstico & 1 & 10 & $14,9 \%$ & 0,851 \\
\hline 23 & Integradora & 1 & 10 & $14,9 \%$ & 0,851 \\
\hline 24 & Pruebas & 1 & 10 & $14,9 \%$ & 0,851 \\
\hline 25 & Emociones & 1 & 9 & $13,4 \%$ & 0,866 \\
\hline 26 & Orientación & 1 & 9 & $13,4 \%$ & 0,866 \\
\hline 27 & Profunda & 1 & 9 & $13,4 \%$ & 0,866 \\
\hline 28 & Sociedad & 1 & 9 & $13,4 \%$ & 0,866 \\
\hline 29 & $\begin{array}{c}\text { Acorde a valores } \\
\text { humanos }\end{array}$ & 1 & 8 & $11,9 \%$ & 0,881 \\
\hline 30 & Asesoría & 1 & 8 & $11,9 \%$ & 0,881 \\
\hline
\end{tabular}

Fuente: elaboración propia 
Tabla 6

Palabras definidoras que obtuvieron el menor peso semántico en la muestra de abogados

\begin{tabular}{ccccc}
\hline $\begin{array}{c}\text { TR (tamaño } \\
\text { de red) }\end{array}$ & Palabras & FR & PS & $\begin{array}{c}\text { DSC (distancia semántica } \\
\text { cuantitativa) }\end{array}$ \\
\hline 57 & Leyes & 1 & 6 & 0,91 \\
\hline 58 & Mente & 1 & 6 & \\
\hline 59 & Método & 1 & 6 & 0,91 \\
\hline 60 & Partes & 1 & 6 & 0,91 \\
\hline 61 & Problemas sociales & 1 & 6 & 0,91 \\
\hline 62 & Psicopatía & 1 & 6 & 0,91 \\
\hline 63 & Psicoanálisis & 1 & 5 & 0,92 \\
\hline 64 & Criminología & 1 & 4 & 0,94 \\
\hline 65 & Forense & 1 & 3 & 0,95 \\
\hline 66 & Arbitraje & 1 & 2 & 0,97 \\
\hline 67 & Probatoria & 1 & 1 & 0,98 \\
\hline
\end{tabular}

Fuente: elaboración propia

Figura 5. Red del estímulo psicología jurídica, a partir de las palabras definidoras obtenidas en el grupo de estudiantes de psicología

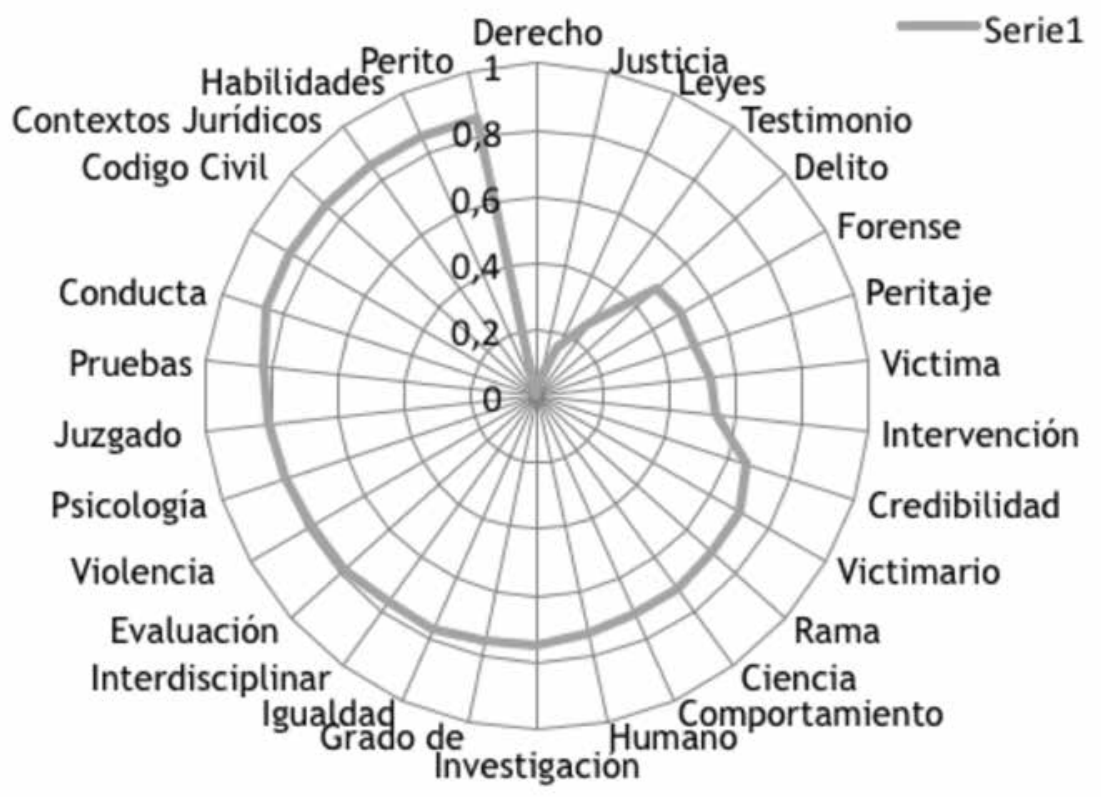

Fuente: elaboración propia

núcleo de la red, le siguen, en orden descendente, las palabras análisis, valoración, comportamiento, derecho, estudio, proceso y pericia, como se puede observar en las figuras 7 y 8 . Vale la pena resaltar que en el núcleo de este concepto aparecen palabras relacionadas con la disciplina con la que generalmente se asocia la psicología jurídica, y con una de las prácticas más comunes, como es la realización de peritajes. 
Figura 6. Distancia semántica de las palabras definidoras del estímulo psicología jurídica, a partir de las palabras definidoras obtenidas en el grupo de estudiantes de psicología.

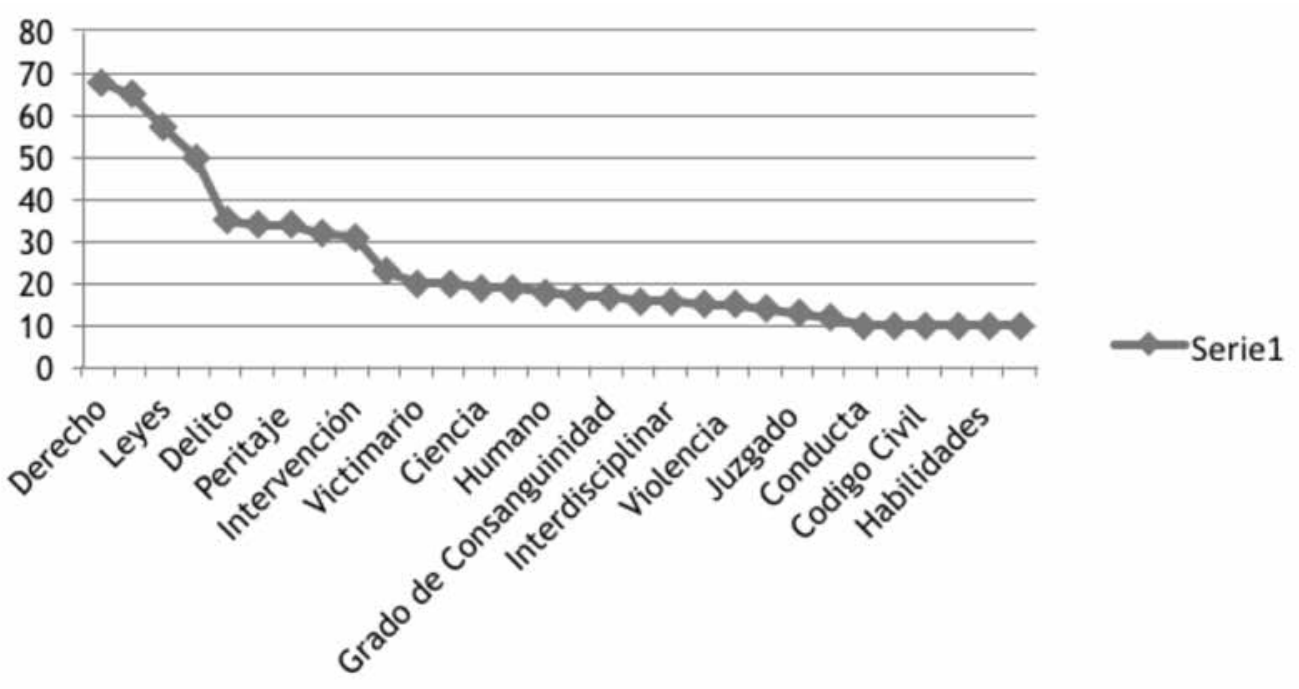

Fuente: elaboración propia

Figura 7. Red del estímulo psicología jurídica a partir de las palabras definidoras obtenidas en el grupo de abogados.

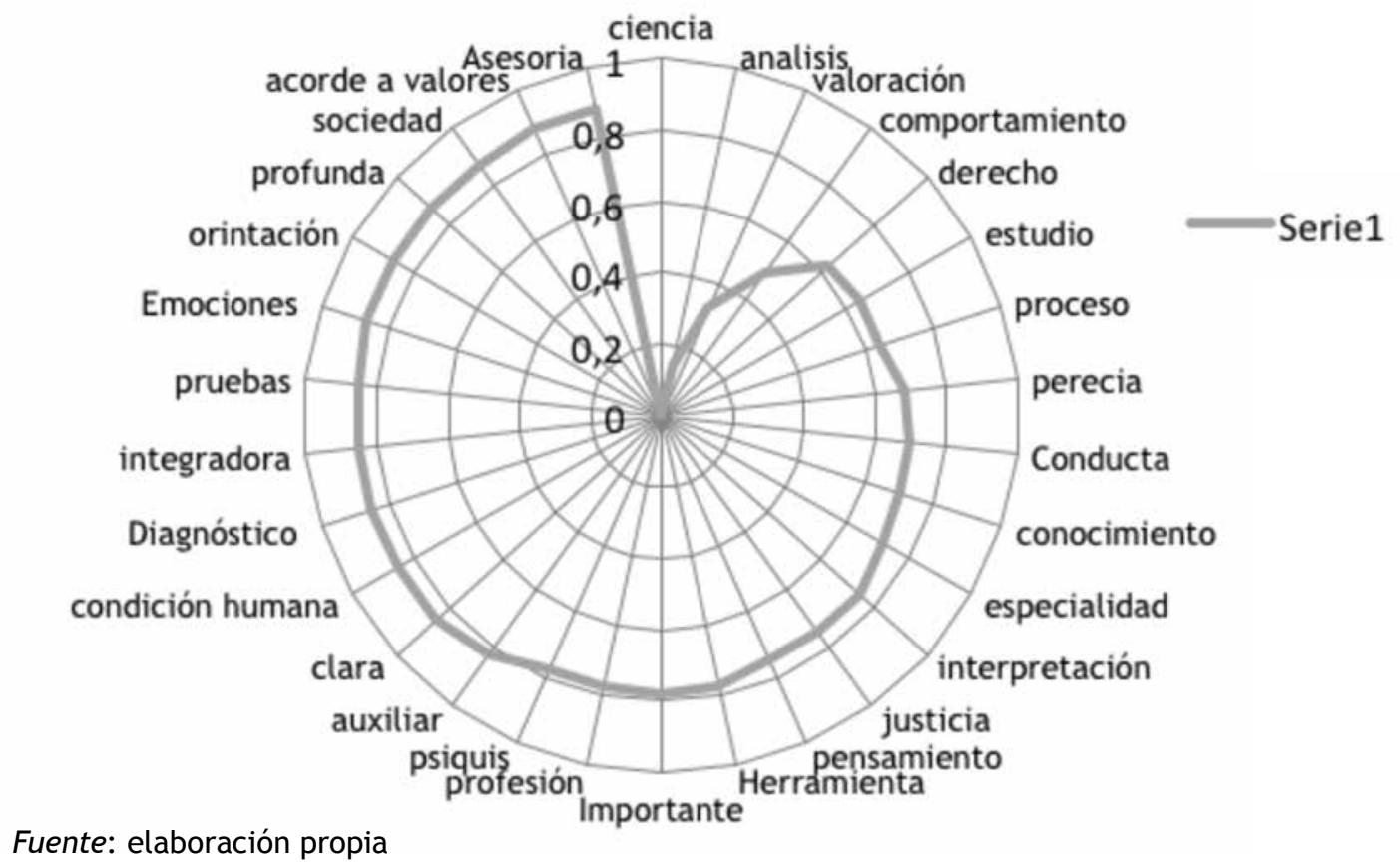

En la tabla 7 se puede observar que los grupos que más palabras comparten son el de psicólogos y el de estudiantes de psicología, mientras que los que menos palabras comparten son el grupo de abogados y el de estudiantes de psicología. Las palabras compartidas por los tres grupos son: comportamiento, conducta, derecho y justicia, lo cual indica que para el total de la muestra, las dos palabras que forman psicología jurídica están muy relacionadas entre sí, ya que muchas definiciones de psicología mencionan que esta es el estudio del comportamiento o de la conducta, y la palabra jurídica invita a pensar en derecho y justicia. 
Figura 8. Distancia semántica de las palabras definidoras del estímulo psicología jurídica a partir de las palabras definidoras obtenidas en el grupo de abogados

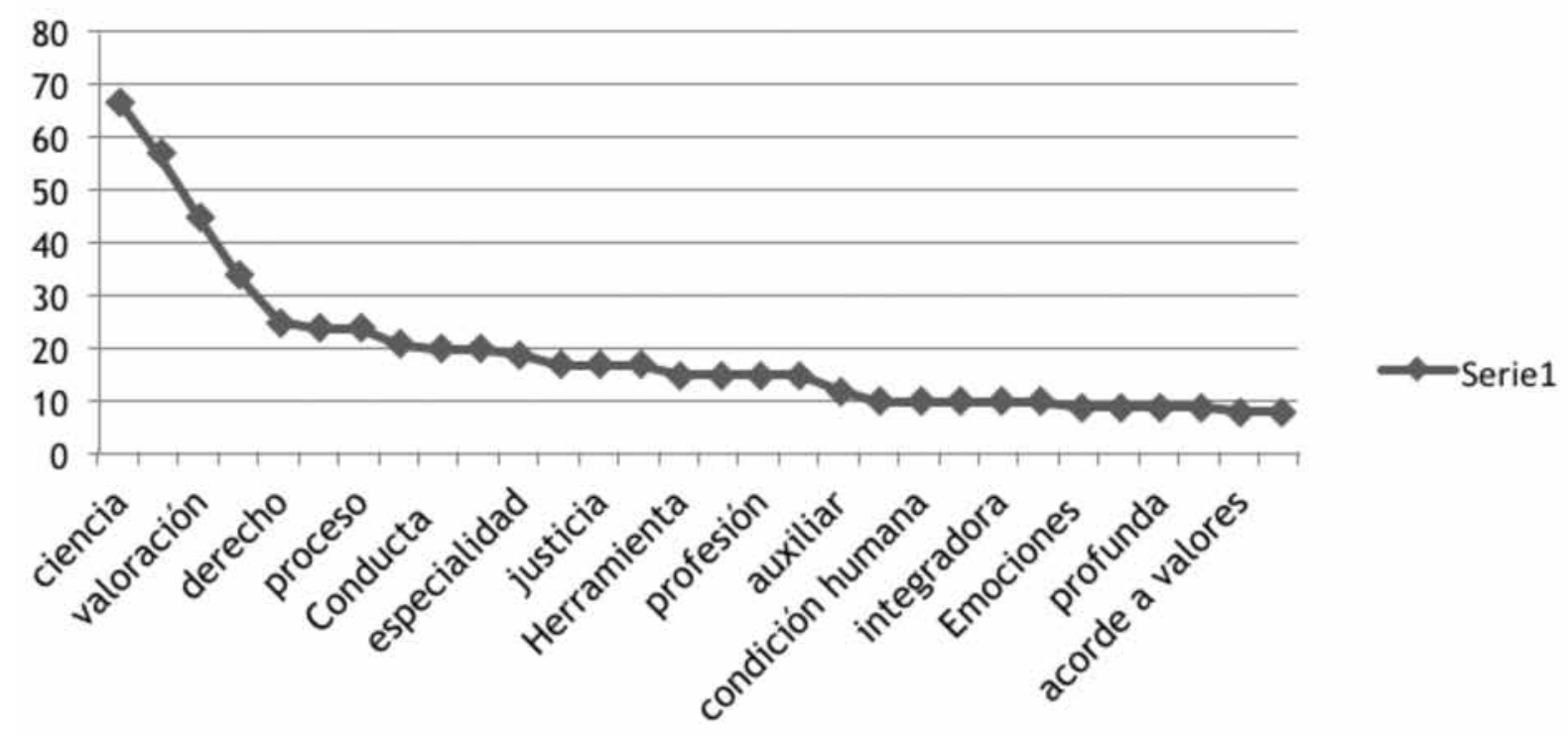

Fuente: elaboración propia

Tabla 7

Definidores compartidos por los grupos

\begin{tabular}{llll}
\hline $\begin{array}{l}\text { Palabras compartidas } \\
\text { por abogados y } \\
\text { psicólogos }\end{array}$ & $\begin{array}{l}\text { Palabras compartidas } \\
\text { por psicólogos y } \\
\text { estudiantes de } \\
\text { psicología }\end{array}$ & $\begin{array}{l}\text { Palabras compartidas } \\
\text { por abogados y } \\
\text { estudiantes de } \\
\text { psicología }\end{array}$ & $\begin{array}{l}\text { Palabras compartidas por } \\
\text { los tres grupos }\end{array}$ \\
\hline $\begin{array}{l}\text { Asesoría, } \\
\text { ciencia, conocimiento } \\
\text { especialidad }\end{array}$ & $\begin{array}{l}\text { Evaluación, forense, } \\
\text { investigación, leyes, } \\
\text { psicología, rama, } \\
\text { testimonio, víctima }\end{array}$ & Prueba & $\begin{array}{l}\text { Comportamiento, conducta } \\
\text { derecho, justicia, pericia, } \\
\text { peritaje, perito }\end{array}$ \\
\hline
\end{tabular}

Fuente: elaboración propia

En la tabla 8 se presentan las palabras que tuvieron mayor peso semántico, organizadas de acuerdo a dos categorías principales (género al que pertenece la psicología jurídica y deferencias especificas con otras áreas de conocimiento) y siete secundarias, que se organizan de acuerdo con las diferencias específicas; estas son: objeto de estudio, escenarios, cualidades, roles, áreas con las que se asocia, competencias y actividades que desempeña. En todas las categorías, los tres grupos comparten significados. 
Tabla 8

Agrupación de palabras con mayor peso semántico en los tres grupos por categorías

\begin{tabular}{|c|c|c|c|c|c|c|c|}
\hline \multirow{2}{*}{$\begin{array}{l}\text { Género } \\
\text { Derecho }\end{array}$} & \multicolumn{7}{|c|}{ Diferencia específica } \\
\hline & $\begin{array}{l}\text { Objetos de } \\
\text { estudio }\end{array}$ & Escenarios & Cualidades & Roles & $\begin{array}{l}\text { Áreas con las } \\
\text { que se asocia }\end{array}$ & Competencias & $\begin{array}{l}\text { Actividades que } \\
\text { desempeña }\end{array}$ \\
\hline Ciencia & Leyes & & Importante & Perito & Forense & Habilidades & Peritajes \\
\hline Especialidad & Comportamiento & Juicio & Clara & & Criminología & & Evaluación \\
\hline Área & Víctimas & Audiencia & Integradora & & Penitenciaria & & Investigación \\
\hline Rama & Justicia & Sociedad & Profunda & & & & \\
\hline Herramienta & Norma & Juzgado & $\begin{array}{l}\text { Acorde a } \\
\text { los valores } \\
\text { humanos }\end{array}$ & & & & Apoyo \\
\hline Profesión & Testimonio & & Igualdad & & & & Asesoría \\
\hline Auxiliar & Conflicto & & & & & & Análisis \\
\hline Interdisciplinar & Proceso & & & & & & Valoración \\
\hline \multirow{11}{*}{$\begin{array}{l}\text { Psicología } \\
\text { Conocimiento }\end{array}$} & Pericia & & & & & & Estudio \\
\hline & Conducta & & & & & & Interpretación \\
\hline & Pensamiento & & & & & & Diagnóstico \\
\hline & Psiquis & & & & & & Pruebas \\
\hline & $\begin{array}{l}\text { Condición } \\
\text { humana }\end{array}$ & & & & & & Orientación \\
\hline & Emociones & & & & & & Intervención \\
\hline & Delito & & & & & & $\begin{array}{l}\text { Aplicación de } \\
\text { instrumentos }\end{array}$ \\
\hline & Credibilidad & & & & & & \\
\hline & Victimario & & & & & & \\
\hline & $\begin{array}{l}\text { Violencia } \\
\text { Contexto legal o } \\
\text { jurídico } \\
\text { Jurídico } \\
\text { Código civil }\end{array}$ & & & & & & \\
\hline & Derecho & & & & & & \\
\hline
\end{tabular}

Fuente: elaboración propia

En la tabla 9 se presentan las palabras que tuvieron menor peso semántico organizadas de acuerdo a dos categorías principales (género al que pertenece la psicología jurídica y deferencias especificas con otras áreas de conocimiento) y siete secundarias, que se organizan de acuerdo con las diferencias específicas; estas son: objeto de estudio, áreas con las que se asocia, competencias y actividades que desempeña, sujetos, características y herramientas. En estas categorías se observa que en general los grupos no comparten significados. 
Tabla 9

Agrupación de palabras con menor peso semántico en los tres grupos por categorías

\begin{tabular}{|c|c|c|c|c|c|c|c|}
\hline \multirow{2}{*}{$\begin{array}{l}\text { Género } \\
\text { Multidisciplinario }\end{array}$} & \multicolumn{7}{|c|}{ Diferencia especifica } \\
\hline & $\begin{array}{l}\text { Objetos de } \\
\text { estudio }\end{array}$ & $\begin{array}{l}\text { Áreas con las } \\
\text { que se asocia }\end{array}$ & Competencias & $\begin{array}{l}\text { Actividades que } \\
\text { desempeña }\end{array}$ & Sujetos & Características & $\begin{array}{l}\text { Herramientas } \\
\text { que utiliza }\end{array}$ \\
\hline Sistema & Pensamiento & Criminología & & Procedimiento & Inocentes & Internacional & Procedimiento \\
\hline \multirow[t]{8}{*}{ Disciplina } & $\begin{array}{l}\text { Problemas } \\
\text { Psicológicos }\end{array}$ & Forense & $\begin{array}{l}\text { Relaciones } \\
\text { interpersonales }\end{array}$ & & Reclusos & Expansión & Método \\
\hline & & & Deber & Empalmar & Personas & Necesaria & \\
\hline & Secuelas & & & Estudio & & Útil & \\
\hline & $\begin{array}{l}\text { Toma de } \\
\text { decisiones } \\
\text { Leyes }\end{array}$ & & & $\begin{array}{l}\text { Incorporar } \\
\text { Arbitraje }\end{array}$ & & Vincular & \\
\hline & Mente & & & Probatoria & & & \\
\hline & Partes & & & & & & \\
\hline & $\begin{array}{l}\text { Problemas } \\
\text { sociales }\end{array}$ & & & & & & \\
\hline & Psicopatía & & & & & & \\
\hline
\end{tabular}

Fuente: elaboración propia

\section{Discusión y conclusiones}

Si bien no existe consenso en torno a la definición de psicología jurídica, también es cierto que parecen existir acuerdos sobre algunos de los elementos que la conforman. De cara al desarrollo de este campo de conocimiento, se hace entonces necesario revisar cuáles son los significados que se activan en torno al estímulo psicología jurídica, entendiendo que los significados son las unidades básicas a partir de las cuales se organizan cognoscitivamente los elementos que crean un código que refleja las disposiciones, expectativas o factores representativos que surgen sobre un término en una cultura particular (Szalay y Mday, 1973), $y$ es por ello que emergen grandes variedades de definiciones, siendo de esta forma diferente el significado que tiene un psicólogo frente a la psicología jurídica del que tiene un abogado.

En los resultados se encuentran diferencias entre los tres grupos que hicieron parte del estudio, y existe un predominio en la conceptualización en términos de objetos de estudio y actividades que realiza el psicólogo jurídico; pero, para la construcción del significado de la palabra, también se acude a categorías como escenarios, cualidades, roles, áreas con las que se asocia y competencias, las cuales permiten organizar dichos significados.
Del mismo modo, se observa que al pensar en los significados de la psicología jurídica, esta suele definirse menos en términos de sujetos y herramientas. No obstante, las palabras con mayor y menor peso semántico comparten una característica en común, y es que la mayoría de definidores guardan una relación estrecha con el ejercicio del derecho, especialmente el probatorio, lo cual no resulta extraño, teniendo en cuenta que el significado de un concepto puede ser evocado en parte gracias a la proximidad de los recuerdos que están relacionados (Collins y Loftus, 1975), y que las palabras que fueron evocadas en esta investigación tienen relación con lo que en diversos textos se ha escrito sobre psicología jurídica. En este sentido, habría sido sorprendente que aparecieran palabras como colegio, proceso de selección, organización o profesores, en la medida que a estos términos no se hace referencia en los textos de psicología jurídica.

Al respecto, Bersh (1981) señala que un concepto es "un pensamiento acerca de las propiedades del objeto, pensamiento que usualmente es el resultado o eslabón final de una serie más o menos larga de juicios o relaciones anteriores" (p. 14). Dicho concepto está constituido, según Mantilla (1995), por nociones aprendidas a lo largo de la vida, y cada nuevo concepto surge a partir de un 
marco de referencia previo que permite compararlo, clasificarlo y delimitarlo para poder diferenciarlo de otros conceptos similares.

Por lo anterior, las palabras asociadas en esta investigación al estímulo psicología jurídica se ven influenciadas por las definiciones tradicionales, como la propuesta por Brown (citado en Kappardis, 2003), según la cual la psicología jurídica "Es la psicología aplicada a los casos de los tribunales, al crimen y su tratamiento, y al estado mental y los procesos", o la propuesta por Mira y López (1932), quien sostiene que "es la psicología aplicada a un mejor ejercicio del Derecho", o la de Clemente (1995), en la que se afirma que

La psicología jurídica es el estudio de las personas y de los grupos, en cuanto tienen la necesidad de desenvolverse dentro de ambientes regulados jurídicamente, así como de la evolución de dichas regulaciones jurídicas o leyes en cuanto que los grupos sociales se desenvuelven en ellos (p. 25).

De otro lado, en todos los grupos se observa una gran riqueza semántica, siendo el grupo de abogados el que produjo, en promedio, un mayor número de definidores, aunque el que grupo que obtuvo el mayor número de palabras fue el de estudiantes de psicología. Esto puede indicar dos situaciones: 1) a mayor número de definidores, menor claridad sobre un concepto, o 2) a mayor número de definidores, mayor claridad sobre el concepto.

Asimismo, se advierte en los resultados que una gran cantidad de definidores en los tres grupos son similares, aunque en cada grupo se le asignen pesos semánticos diferentes, lo cual puede deberse, como lo señalan Stewart y Stasser (1995), a que la presencia de un experto en un grupo afecta el reconocimiento de conceptos durante la recuperación de los recuerdos.

En el caso de esta investigación, se asumen como expertos los autores de los libros sobre psicología jurídica y los docentes que imparten cátedras de pregrado y posgrado en este campo de conocimiento, quienes en muchos casos han sido compartidos por los grupos de personas que hicieron parte de esta investigación, de modo que esta si- tuación puede explicar por qué tantos definidores guardan similitudes. Según Kameda, Ohtsubo y Takezawa (1997), la información compartida parece tener una influencia sobre los consensos.

Según Miaja (2001), una manera de construir conceptos es a partir de las definiciones, las cuales tienen como fin identificar y explicar el significado de una palabra a partir de dos elementos: el definiendum, que es la palabra o grupo de palabras que han de definirse (en nuestro caso, psicología jurídica) (Bunge, 2000), y el definiens, que será la palabra o grupo de palabras que se utilizarán para conformar la definición (en este caso, las palabras encontradas a partir de las redes semánticas) (Rickert, 1960; Mardones, 2006; José, 2006; Buela-Casal y Sierra, 1997; Lázaro,1996).

El definiens debe contener el género, que indica la especie a la que pertenece aquello que quiere definirse, y la diferencia específica, que es la que indica lo que hace que aquello que se define se diferencie de otros conceptos (Rickert, 1960). Otra forma es a partir de redes semánticas, las cuales permiten organizar los significados (Quilian, 1967). A partir de ello, se organizaron las palabras de los tres grupos (psicólogos, abogados y estudiantes de psicología) en estos dos elementos (género y diferencia específica), los cuales han servido como categorías para organizar los resultados.

En primer lugar se encontró que algunas de las palabras relacionadas con el género, como derecho, ciencia, auxiliar, interdisciplinar y psicología, coinciden con lo hallado por Gutiérrez de Piñeres (2011), quien mostró que muchos de los autores que intentan definir la psicología jurídica hablan de ella como una ciencia (Toch, citado en Tapp, 1980;); como un campo interdisciplinar (Carson, Milne y Pakes, 2007; Munné, Muñoz y Bayés, 1980; Ogloff, 2001; Nin, 2002); como un área que pertenece a la psicología (Brown, citado en Kappardis, 2003; Mira y López, 1980); como un área que pertenece al derecho (Radbruch, 2002); o como un área auxiliar (Mira y López, 1980).

Llama la atención, sin embargo, que en la misma revisión hecha por Gutiérrez de Piñeres (2011), ningún autor la define utilizando palabras como especialidad, área, conocimiento, rama, herra- 
mienta o profesión, expresiones que sí fueron utilizadas por los participantes de este estudio. Esto nos lleva nuevamente al debate acerca de qué es la psicología jurídica. Recordemos que en 2005, Díaz escribía:

es claro que todos los que nos dedicamos a este campo la entendemos como el escenario del conocimiento, que utiliza los hallazgos y avances de la ciencia psicológica para intentar comprender los acontecimientos que se dan en el ámbito legal, una vez que el hombre entra en contacto con él. (p. 3).

No obstante, en los resultados se observó que quienes se dedican al ejercicio de este campo de conocimiento, es decir los psicólogos, refieren en su mayoría que la psicología jurídica se relaciona con el derecho, más que con la psicología misma, lo cual puede hacernos pensar que quizás no sea tan claro para "los que nos dedicamos a este campo" lo afirmado por Díaz.

En segundo lugar, Gutiérrez de Piñeres (2011) propuso agrupar los objetos de estudio que se planteaban en las definiciones en dos grupos: 1) los que consideran que el objeto de estudio es el derecho o las ciencias jurídicas, incluyendo la práctica del derecho y los actores jurídicos; y 2) los que consideran que los objetos de estudio son los supuestos psicológicos, los fenómenos psicológicos y psicosociales, y el comportamiento de las personas que alcanza una consecuencia jurídica.

En esta investigación, en la que participaron tanto psicólogos (profesionales y en formación) como abogados, se encontró que los tres grupos coinciden en decir que tanto la conducta como el comportamiento y el derecho forman parte del significado que se tiene de la psicología jurídica, y que el grupo de psicólogos y estudiantes de psicología coinciden en objetos de estudio como víctima, testimonio y leyes.

Una tercera forma de agrupar las palabras identificó aquellas que hacían mención a las posibles funciones que podría desempeñar un psicólogo jurídico; dentro de estas, las que tuvieron un mayor peso semántico fueron peritajes, evaluación, investigación, apoyo, asesoría, análisis, valoración, estudio, interpretación, diagnóstico, pruebas, orientación, intervención, aplicación de instrumentos. Estas palabras guardan relación con el campo de la psicología jurídica que mayor desarrollo ha tenido: la psicología forense.

Es así como Toch (citado en Tapp, 1976) propone que una de las funciones de la psicología jurídica es la de evaluar a las personas que hacen parte en procesos de justicia. En conjunto, estas palabras se asocian con lo que Muñoz (1998) denominara psicología para el derecho o psicología para la ley, al tratarse de una psicología probatoria (Rico, 1997). Cabe resaltar que de todas las palabras que surgieron en la investigación no se encuentran palabras que no tengan algún tipo de relación con el término psicología jurídica.

De otro lado, al utilizarse las redes semánticas como herramienta que permite identificar los significados y conceptos que las personas manejan en su memoria sobre un término, puede conocerse cómo aquellas organizan el conocimiento sobre las palabras y los símbolos, y cómo construyen relaciones entre los diferentes conceptos, para generar reglas que les permitan manipular dichos símbolos y conceptos.

En el caso de la psicología jurídica, esta investigación permitió conocer los significados que psicólogos, estudiantes de psicología y abogados construyen en torno al concepto, el cual actuó, según la postura de Collins y Loftus (1975), como blanco, activando los siguientes estímulos:

- Sobre el género al que pertenece, puede concluirse que los participantes piensan que la psicología jurídica se relaciona con el derecho, con una ciencia, con una especialidad, una rama, un área, una profesión, un campo interdisciplinario, o que es una herramienta que sirve de auxiliar.

- Sobre los objetos de estudio, los participantes escribieron los siguientes definidores: leyes, comportamiento, víctimas, justicia, norma, testimonio, conflicto, proceso, pericia, conducta, pensamiento, psiquis, condición humana, emociones, delito, credibilidad, victimario, entre otras. 
- Sobre las áreas de conocimiento con las que se relaciona, algunas de las palabras utilizadas fueron: forense, criminología, penitenciaria, victimología.

- Sobre los espacios, lugares o escenarios, los participantes mencionaron, entre otras, las siguientes palabras: juicio, audiencia, sociedad, juzgado y cárcel.

- Sobre las acciones, roles, funciones y actividades, los participantes escribieron las siguientes palabras: perito, peritaje, evaluación, investigación, apoyo, asesoría, análisis, apoyo, valoración, estudio, interpretación, aplicación de pruebas o instrumentos, orientación e intervención.

De otro lado, se observa que los tres grupos comienzan a relacionar la psicología jurídica con campos de conocimiento -derecho y ciencia-, más que con una técnica o con un quehacer, los cuales, si bien si aparecen dentro de los definidores, no son los que mayor peso semántico tienen.

A manera de conclusión, puede indicarse que definir un área de conocimiento no es una tarea fácil, y la proliferación de definiciones del término psicología jurídica demuestra que este campo no es la excepción. Esta multiplicidad de definiciones ha generado un impacto sobre el concepto mismo, toda vez que pone de manifiesto la ausencia de conceso frente a lo que la psicología jurídica es.

Por un lado esta situación puede resultar positiva, ya que demuestra la riqueza en los debates sobre su alcance, pero también puede ser perjudicial, en la medida en que dificulta precisar y delimitar las actuaciones al interior de esta área, como lo afirman Buela-Casal y Sierra (1997). No obstante, en la presente investigación pudo observarse que, si bien no existe consenso o acuerdo, las nociones generales no distan mucho las unas de las otras.

También llama la atención que para los psicólogos y estudiantes de psicología la palabra que tuvo mayor peso semántico fue derecho, mientras para los abogados fue ciencia. Esto pone de manifiesto la discusión que por varios años se ha tenido acerca de la relación que existe entre psicólogos y abogados que trabajan en escenarios judiciales o en favor de la justicia, pues se ha debatido si en relación con el derecho y los abogados, el psicólogo cumple una labor de auxiliar o asesor (Díaz, 2008, Tapias, 2011).

El hecho de que los psicólogos entiendan una especialidad de su profesión referida al vocablo derecho puede suponer que, pese a las críticas, son estos profesionales los que más acentúan el ejercicio psicojurídico como referido o dirigido al derecho, y no viceversa. Para los psicólogos y estudiantes de psicología pareciera que la psicología jurídica se encuentra más relacionada con el derecho que con la psicología misma, mientras que los abogados parecen haber comprendido que el terreno de encuentro entre psicología y derecho es más neutral, al atribuirle el status de ciencia a la psicología jurídica.

De otro lado se observó que en general los tres grupos evocan términos como perito, peritaje, peritación, evaluación o valoración. Estas palabras guardan relación con uno de los ejercicios más reconocidos y practicados por los psicólogos jurídicos, como lo es la psicología forense, subárea que históricamente ha sido la de mayor campo de aplicación laboral para quienes se interesaban por este campo de conocimiento. Estos términos evidencian cómo uno de los ejercicios por los cuales se reconoce con mayor frecuencia la psicología jurídica es el de servir como auxiliares de la justicia, lo cual conduce de nuevo a un debate presente por mucho tiempo en la psicología jurídica, y a la discusión sobre si esta es en realidad un área aplicada de la psicología con estatus científico, o si es simplemente la aplicación de una serie de técnicas.

Vera, Pimentel y Baptista de Albuquerque (2005) sostienen que en una red semántica

el peso se satura en la primeras definidoras. Cuando la saturación ofrece un punto de corte anterior a las diez definidoras, el concepto puede decirse tiene precisión y es homogéneo entre la población. Cuando ultrapasa el valor de 10, el concepto suele ser ambiguo y tendrá que trabajarse con un multisignificado (p. 11).

En el caso de los tres grupos que participaron en este estudio, los pesos semánticos no alcanzaron 
la máxima saturación en los diez primeros definidos, por lo tanto, el concepto de psicología jurídica parece ser impreciso y ambiguo.

La investigación ha demostrado que aunque a la fecha no hay consenso sobre el significado de la psicología jurídica, la brecha entre las distintas concepciones se torna menos extensa, lo que supone que con el paso del tiempo, y la cada vez más prolija producción y preparación de los psicólogos jurídicos, en un futuro no muy lejano la comunidad científica de esta disciplina podrá estructurar de mejor forma su cuerpo de conocimiento, objetos de estudio y escenarios de acción.

Si bien la apuesta no pretende unificar o negar la posibilidad de nuevas formas de pensar este ejercicio profesional, sí pretende establecer o erigir unos principios o postulados que le resulten propios y que permitan delimitar epistemológicamente su naturaleza y alcances, todo ello en beneficio de los usuarios o destinatarios de los servicios prestados por psicólogos jurídicos en el país y el mundo entero.

\section{Referencias}

Alvaro, J., Garrido, A., Schweiger, I., y Torregrosa, J. (2007). Introducción a la psicología social sociológica. Barcelona: UOC.

Bersh, D. (1981). El fenómeno de la salud. Bogotá: OPS, OMS/ASCOFAME.

Buela-Casal, G., y Sierra, C. (1997). Manual de evaluación psicológica: Fundamentos, técnicas y aplicaciones. Madrid: Siglo XXI.

Bunge, M. (2000). La investigación científica. Buenos Aires: Siglo xxı.

Carson, D. Milne, R., \& Pakes, F. (2007). Applying psychology to criminal justice. New Jersey: John Wiley and Sons.

Chomsky, N. (1971). Lenguaje y Pensamiento. Rio de Janeiro: Vozes.

Clemente, M. (1995). Fundamentos de la Psicología Jurídica. Madrid: Pirámide
Collins, A., \& Loftus, E. (1975). A spreading-activation theory of semantic processing. Psychological Review, (82), 407-428.

Cole, R., y Scribner, S. (1977). Cultura y Pensamiento. México: Limusa.

Díaz, F. (2008). Psicología jurídica latinoamericana: Reflexión sobre su quehacer. En A. Tapias, y C. Gutiérrez de Piñeres (Eds.), Psicología jurídica: Perspectiva latinoamericana. Bogotá: Psicologíajurídica.org.

Domínguez, A. (s. f.). Desarrollo de las redes semánticas naturales Modificadas. Bogotá. (No publicado).

Figueroa, J., González, E., y Solís, V. (1981). Una aproximación al problema del significado: Las redes semánticas. Revista Latinoamericana de Psicología. 13 (3), 447-458

Freedman, J., Carlsmith, J., y Sears, D. (1970). Comunicación y desempeño. Sao Pablo: Cultrix.

Gutiérrez de Piñeres, C. (2011). Conceptos de psicología jurídica a partir de su historia y definiciones. Trabajo de maestría inédito. Facultad de Psicología, Santo Tomás, Bogotá.

José, E. (2006). Conocimiento, pensamiento y lenguaje: Una introducción a la lógica y al pensamiento científico. Madrid: Biblos.

Kameda, T., Ohtsubo, Y., \& Takezawa, M. (1997). Centrality in sociocognitive networks and social influence: An illustration in a group decision-making context. Journal of Personality and Social Psychology, 73(2), 296-309.

Kangassalo, H. (1992). On the concept of concept for conceptual modelling and concept detection. En S. Ohsuga (Ed.), Information modelling and knowledge bases (Vol. 5). Amsterdan: IOS Press.

Kapardis, A. (2003). Psychology and law: a critical introduction. Reino Unido: Cambridge University Press

Labastida, J. (2007). El Edificio de la Razón. Madrid: Siglo XXI. 
Lázaro, J. (1996). El pensar lógico. Nueva York: Universidad de Puerto Rico.

Ley del Psicólogo, Ley 1090, 2006.

Mantilla, W. (1995). El Científico y La Ciencia. Bogotá: Unisur y Mantilla.

Mardonés, J. (2006). Filosofía de las Ciencias Sociales y Humanas. Colombia: Anthhropos.

Miaja, C. (2001). Lógica. México: Pax.

Mira y López, E. (1980). Manual de psicología jurídica. Buenos Aires: Ateneo.

Munné, F., Muñoz, S., y Bayés, R. (1980). Introducción a la psicología jurídica. México. Trillas.

Nin, A. (2002). La psicología jurídica en Uruguay. En J. Urra (Ed.), Tratado de psicología forense. Madrid: Siglo xxI.

Ogloff, J. (2001). Jingoism, dogmatism and other evil in legal psychology: Lessons learned in the $20^{\text {th }}$ century. En R. Roesch, R. Corrado, $y$ R. Dempster, (Eds.) Psychology in the courts: International advances in knowledge. US: Routledge.

Pautas éticas internacionales para la investigación biomédica en seres humanos. (2002). Preparadas por el Consejo de Organizaciones Internacionales de las Ciencias Médicas (CIOMS) en colaboración con la Organización Mundial de la Salud. http://www.ub.edu/rceue/archivos/ Pautas_Eticas_Internac.pdf

Pfander, A., \& Ferrari, D. (2009). Logic. Berlín: Ontos Verlag.
Quillian, M. (1967). Semantic memory. En M. Minsky (Ed.). Semantic information processing (pp. 27-70). Cambridge, MA: MIT Press.

Radbruch, G. (2002). Introducción a la filosofía del derecho. México: Fondo de Cultura Económica.

Reyes, I. (1993). Las redes semánticas naturales, su conceptualización y su utilización en la construcción de instrumentos. Revista de Psicología Social y Personalidad, 9 (1), 81-97.

Rickert, H. (1960). Teoría de la definición. México: UNAM.

Rico, M. (1997). Las ciencias sociales y el derecho. En M. Clemente (Ed.). Fundamentos de la psicología jurídica. Madrid: Pirámide.

Szalay, L., \& Maday, B. (1973). Verbal Associations in the analysis of subjetive culture. Current Anthropology, 14, 151-173.

Stewart, D., \& Stasser, G. (1995). Expert role assignment and information sampling during collective recall and decision making. Journal of Personality and Social Psychology, 69, 619-628.

Tapp, J. L. 1980: Psychological and policy perspectives on the law: Reflections on a decade. Journal of Social Issues, 36, 165-192.

Vera, J., Pimentel, C., y Batista de Albuquerque, F. (2005). Redes semánticas: Aspectos teóricos, técnicos, metodológicos y analíticos. $R a$ Ximhai, 1(3), 439-451. 